\title{
Predicting adoption of location-based social media service in travel decisions
}

\begin{abstract}
Advances in location-acquisition and mobile communication technologies have empowered people to use location-based social media. However, the technologies are relatively new, and literature on the relevant factors determining location-based social media adoption. We examine if the online information reviews information can predict users' location-based social media usage for travel planning. The results of this study will be useful for location-based social media providers in formulating appropriate marketing strategies and in developing applications that will attract more users.
\end{abstract}

Keywords: Location-based social media, travellers' decisions, technology acceptance, mobile commerce

\section{INTRODUCTION}

Users today relied heavily on the information they found from the Internet to help make their purchasing decisions. Instead of searching information online from their computers, users are increasingly searching online using their mobile devices. As a result, mobile Internet and mobile commerce have captured the attention of both practitioners and researchers due to their potential impact on business and industry (Chong 2013). Unlike e-commerce, mobile Internet offers the advantage that users can go online anytime, anywhere. With better and faster mobile Internet bandwidth, it is common for consumers to use their mobile devices to search for product and service information, and to conduct mobile commerce-related activities. A recent report by comScore, an Internet marketing research company, finds that web searches on desktops declined in September 2012 while Internet search traffic coming from smartphones and tablets is growing (Newton 2012). The growth of mobile Internet suggests that mobile commerce has the potential to overtake e-commerce as the medium through which consumers conduct their online transactions and purchases (Klein and Kozlowski 2000; Williamson 1993).

The advancement on mobile technology has started to receive attention in tourism research with its potential impacts and practical applications (Kim and Fesenmaier 2008; MacKay and Vogt 2012). One of the advantages of mobile commerce when compared to e-commerce is the ability to offer location-based services. Location-based services include many offerings for consumers such as finding friends (e.g. What's Up), updating one's location for friends on a social network (e.g. Facebook), and advertisements (e.g. AdLocal). One promising area of location-based service is the customization of products and services search results based on travellers' locations (Barragáns-Martínez and Costa-Montenegro 2012). Most travellers today have the option of replacing their maps with digital maps on their mobile devices through Global Positioning Systems (GPS). GPS is now available on most smart phones. The advantage of using GPS when compared to a traditional map is the ability to help travellers navigate by tracking their current position, and by providing real-time directions and information about nearby attractions to travellers. However, with the emergence of mobile Internet, companies are able to extend location-based services by integrating them with social media services. Location-based social media allows consumers to receive recommendations for nearby attractions, read reviews and ratings by other consumers, and enables them to provide reviews and ratings of attractions. Examples of this include the FourSquare, Facebook's Nearby, Google plus and Yelp. Using location-based social media, consumers can search for nearby attractions, and by identifying the consumer's location, the application is able 
to provide a list of potential destinations (e.g. restaurants or museums), and the reviews of these attractions which are generated by other consumers. When travellers rely on the search results from location-based social media applications, the consumer-generated reviews that accompany the results can significantly influence their decisions (Zhu and Zhang 2010). This is because travellers may be new to the location and will rely on others' opinions for decisionmaking and therefore are more likely to trust their peers' opinions than to rely on marketerinitiated sources (Ludwig et al. 2013). Location-based social media tools such as Foursquare and Yelp have provide a new form of interactions between customers and the physical location of a business (Honigman 2013).

Despite the growing interest in mobile commerce and location-based social media applications, most mobile users are still using their mobile devices for activities related to text messaging, music searching and downloads, and mobile game playing (Chong et al. 2012). Ayeh et al. (2013) stated that in travel planning, for example, many Internet users are not yet utilizing consumer-generated media such as consumer reviews for their travel planning (Banyai 2012). A recent report by DCCI, a Chinese Internet research company, found that only 7 present of mobile phone users in China use mobile location-based services. China has one of the largest numbers of mobile phone users, and this presents great opportunities for businesses and location-based social media application providers (Chong et al. 2012).

The low utilization of location-based social media service can be caused by various factors. Firstly, it could be related to issues involving consumers' willingness to adopt the locationbased mobile service during their travel. Some questions such as the cost of $3 \mathrm{G}$ roaming service and the perceived usefulness of the application can play a role in consumers' adoption decisions. Secondly, location-based social media offer consumers' reviews and ratings which affect their decisions to choose the travel and attraction recommendations. However, current research on online reviews in both information systems and tourism offers little guidance on users' travel planning decisions based on the reviews. For example, In Mansson's (2011) research on the consumption of social media suggests that tourist becomes a rather passive media consumer who is seen only as a user of media products (Månsson 2011) and Ludwig et al. (2013) took the linguistic approach to examine the effectiveness of words used in review (Banyai 2012; Ludwig et al. 2013; Månsson 2011). The gap still existed on how this information could lead to the actual decision on travel planning. In particular, there are only limited research in Tourism which focus on the credibility of online reviews in the context of location-based social media (Ayeh et al. 2013).

One industry in particular which location-based social media can play a major role is the travel industry. Location-based social media enables travel-related companies to promote their products and brands, gets people on social networks involved and motivated to travel, and allows the targeting of key market segments (Litvin et al. 2008). Location-based social media such as Foursquare allows users to deliver "word-of-mouth" marketing for businesses, which is one of the most important influencers when it comes to consumers' travel decisions. A recent survey by Tourism-Review.com indicates that more than two thirds of travellers today state that traveller reviews websites are influential and important when planning leisure trips.

Given the growing attention on the impact and adoption of location-based social media applications on the vacation behavior and experiences of travelers on pre-trip planning and information search (MacKay and Vogt 2012; White and White 2007; Zheng Xiang et al. 2008), the limited studies regarding this topic is surprising. This paper aims to examine the factors that can predict travelers' adoption of location-based social media services for travel planning. 
In this research, "travel planning" is defined as the pre-travel planning decisions (e.g., using location-based social media to assist in travel decisions) of a traveler. The objective of this research predict the types of online review information which can influence the use of location based social media for travel plannings. The paper is organized as follows. First, we review existing literature. We then explain the methods used in the study and discuss our research findings. Finally, the conclusion and implications of the study are presented.

\section{THEORETICAL BACKGROUND AND HYPOTHESES DEVELOPMENT}

\subsection{Location-based social media for travel planning}

Location-based services and social media are both applications which have been gaining popularity in recent years. The advancement of mobile technologies (e.g. GPS, Wi-Fi availability, 4G) and better mobile Internet bandwidth have empower users with the ability to add location dimension to their existing social networks (Gao et al. 2012). For example, users can now share their current location and upload a location tagged photo on their Facebook. Location-based social media allows users to bridge the gap between the physical world and the social networking services (Zheng 2011). This has potential significant implications to travel companies leveraging on social media to reach out to their customers. For example, a user can leave a comment about a restaurant he or she just visited in his or her social networking site. As a result, people connected to the user's social network can reference to the comments when they visit the restaurant later (Zheng 2011). As a result, users have created and shared their location-based information in the physical world and at the same time, are able to browse each other's information in the social networking site (Zheng 2011). Location-based social media not only allows users to share and track their location related information, they also allowed users to add new social network connections based on information learned from the application. For example, people who enjoy visiting the same or similar shops or tourist spots (e.g. amusement theme parks) can connect to each other.

Location-based social media has great potentials to businesses as not only does it offers users to share location related information, they also allow users to share and learn information derived from the location and user generated contents (Zheng 2011). For example, selecting a particular restaurant based on the reviews and photos shared by existing customers. As a result, it is useful for businesses that plan to use location based social media as their marketing and business strategies to understand what influence travellers' adoption of location-based social media for their decision making process.

As location-based social media is the integration between location-based service and social media, understanding travellers' adoption of the technology becomes more complicated than traditional information systems adoption. This is because travellers are not only considering whether they will adopt the application, at the same time, they will also decide if they will adopt the user-generated contents in the application such as the reviews by other users.

Past studies on information systems tended to examine the adoption of location-based services, mobile applications, or user-generated content from social media or e-commerce Web sites individually. Not surprisingly, as a newly developed phenomenon, research in the area of tourism has been limited to investigating the applications and usage of local-based social media. The results of these studies mainly focus on the context of travel-related searches of social media in search engines (Xiang and Gretzel 2010), the convergence of information (Månsson 2011), their uses as marketing and strategic tools for travelers (Banyai 2012), and 
the credibility issues with user-generated content (Ayeh et al. 2013). Therefore, a new model is required for us to understand the adoption decisions of users in location-based social media.

\subsection{Online reviews and location-based social media adoption for travel planning}

One important aspect of location-based social media is the ability to provide reviews on the attractions that travelers intend to visit. In today's Internet environment, consumers can easily contribute their thoughts and opinions on products and services through reviews and ratings (Lee and Lee 2009). Google and Baidu are examples of companies that offer location-based social media, which allows users to contribute their thoughts and opinions on products and services, usually on attractions such as restaurants, museums, theme parks, and other tourist destinations. Given that these reviews are provided by people whom the travelers may or may not know, understanding how users are influenced by the review information on location-based social media is important. Previous literature has presented various theories, such as Dual Process Theory, Yale Model, and Elaboration Likelihood Model, (ELM) to explain how users are influenced by the argument strengths and source credibility of online reviews (Cheung et al. 2009; Papathanassis and Knolle 2011). Argument quality is the persuasive strength of the argument in the reviews, and source credibility is the credibility of the reviews (Cheung et al. 2008). The present study includes the attributes of argument quality and source credibility of online reviews as predictors of the adoption of location-based social media for travel planning.

\subsubsection{Argument Quality}

In a social media environment, consumers' decisions to purchase or use a product or service based on online reviews is determined by the perceived quality of the information received (Cheung et al. 2008). Therefore a traveller's perception of the quality of the reviews and ratings will influence his or her use of location-based social media in travel planning. Argument quality in this study is defined as the persuasive strength of arguments in the location-based social media reviews (Bhattacherjee and Sanford 2006).

For this study, argument quality is measured by argument strength, review rating, and timeliness of the reviews.

Argument strength is defined as the extent to which the traveller views a review's argument as convincing or valid in supporting its position (Cheung et al. 2009). If the reviews are perceived to have valid arguments, the traveller will in turn develop a positive attitude towards the information and will treat it as credible. On the other hand, invalid arguments from the reviews will lead to a negative attitude toward the reviews, and the travellers may be less inclined to use the information in travel planning. Cheung et al. (2009) in their study on online forum discussions, have supported the positive relationship between argument strength and the credibility of online consumer recommendations.

Review rating is the overall rating by other users of the location-based social media on the reviews. Most location-based social media or social media applications allow users to evaluate and rate the reviews written by other users. Studies by Hu et al. (2008) and Cheung et al. (2009) have found that review ratings can influence the perceptions of the information received from the reviews.

The timeliness of the reviews refers to whether the reviews are up to date. Given that many products and services change rapidly, it would be risky for travellers to plan their travel based 
on outdated reviews. DeLone and McLean (1992), in their model for assessing systems quality, stated that information quality is determined by the timeliness of the information. Liu et al. (2008) also found that online reviews' helpfulness can be predicted by their timeliness.

Based on the discussions above, the following hypotheses are proposed:

Hla: Argument strength has a significant and positive relationship with users' intention to adopt location based social media for their travel planning.

H1b: Review rating has a significant and positive relationship with users' intention to adopt location based social media for their travel planning

H1c: Timeliness of the reviews has a significant and positive relationship with users' intention to adopt location based social media for their travel planning

\subsubsection{Source Credibility}

Credibility in this study is defined as the extent to which the user perceives the review from location-based social media as believable. Extending the definition of Cheung et al. (2009), in this research credibility refers to trusting the person contributing to the review as well as trusting the online review itself. Credibility of word of mouth has long been an interest of persuasion research, and reviews with high credibility are often found to be more persuasive than those with low credibility (Petty and Wegener 1998; Tormala and Petty 2004). We believe that this is the same in the context of electronic word of mouth which is found in location-based social media's reviews. In this study, source credibility is examined using reviewer trustworthiness, review consistency, review sidedness and reviewer expertise.

Given that people are allowed to contribute to online reviews while remaining anonymous, it is important that reviews are perceived as credible before the information is adopted. Unlike traditional media, the Internet does not have government or ethical regulations controlling its content (Eastin 2001). Together with the fact that new information is constantly being added at a rapid pace, this presents a new problem for users who are searching for information, as credible sources are increasingly becoming more difficult to differentiate from less credible sources (Eastin 2001). One way that users may perceive the person contributing to the review as being credible is by examining the expertise of the contributor as well as his or her trustworthiness (Wiener and Mowen 1986). Expertise and trustworthiness are both two of the most widely cited variables in assessing credibility of sources in the study of various fields such as marketing, advertising and recreation behaviour management (Patzer 1983). Consistent with previous studies, we believe that in the context of location-based social media, reviews will be viewed as more credible if they are posted by other consumers who have a high level of expertise and trustworthiness.

Besides evaluating whether the person contributing the reviews is credible, it is also important to examine whether the reviews themselves are credible. There are factors that may influence how the reviews are perceived by the users - the review's consistency, and the review's sidedness. The review's consistency is defined as how consistent the review is with other contributors' evaluation of the product or service evaluation (Cheung et al. 2009; Cheung et al. 2007). Given that everyone is allowed to contribute to online reviews, there is a risk that some 
reviews are strongly biased, either in a positive or negative way. A user is likely to view a particular review as being credible if it is consistent with the opinions of other users. Besides being consistent, users will also feel that a review is credible if reviews are two sided (Cheung et al. 2009). In a two-sided review, both positive and negative comments are present, and for the reader, two-sided comments will tend to be viewed as more credible as they can reduce the receiver's scepticism. Such a view is supported by the attribution theory in marketing research (Lang et al. 1997). However, it is also common in websites such as Taobao whereby sellers offer buyers incentives to change negative comments into positive comments. Nevertheless, in the case of Taobao, it is not known whether sellers who have received only positive comments will experience improved sales.

Based on the above discussions, the following hypotheses are proposed:

H2a: Reviewer trustworthiness has a significant and positive relationship with users' intention to adopt location based social media for their travel planning.

H2b. Review consistency has a significant and positive relationship with users' intention to adopt location based social media for their travel planning

H2c. Review sidedness has a significant and positive relationship with users' intention to adopt location based social media for their travel planning.

H2d Reviewer expertise has a significant and positive relationship with users' intention to adopt location based social media for their travel planning.

Figure 1 presents the research model for this study.

Figure 1 Research model 


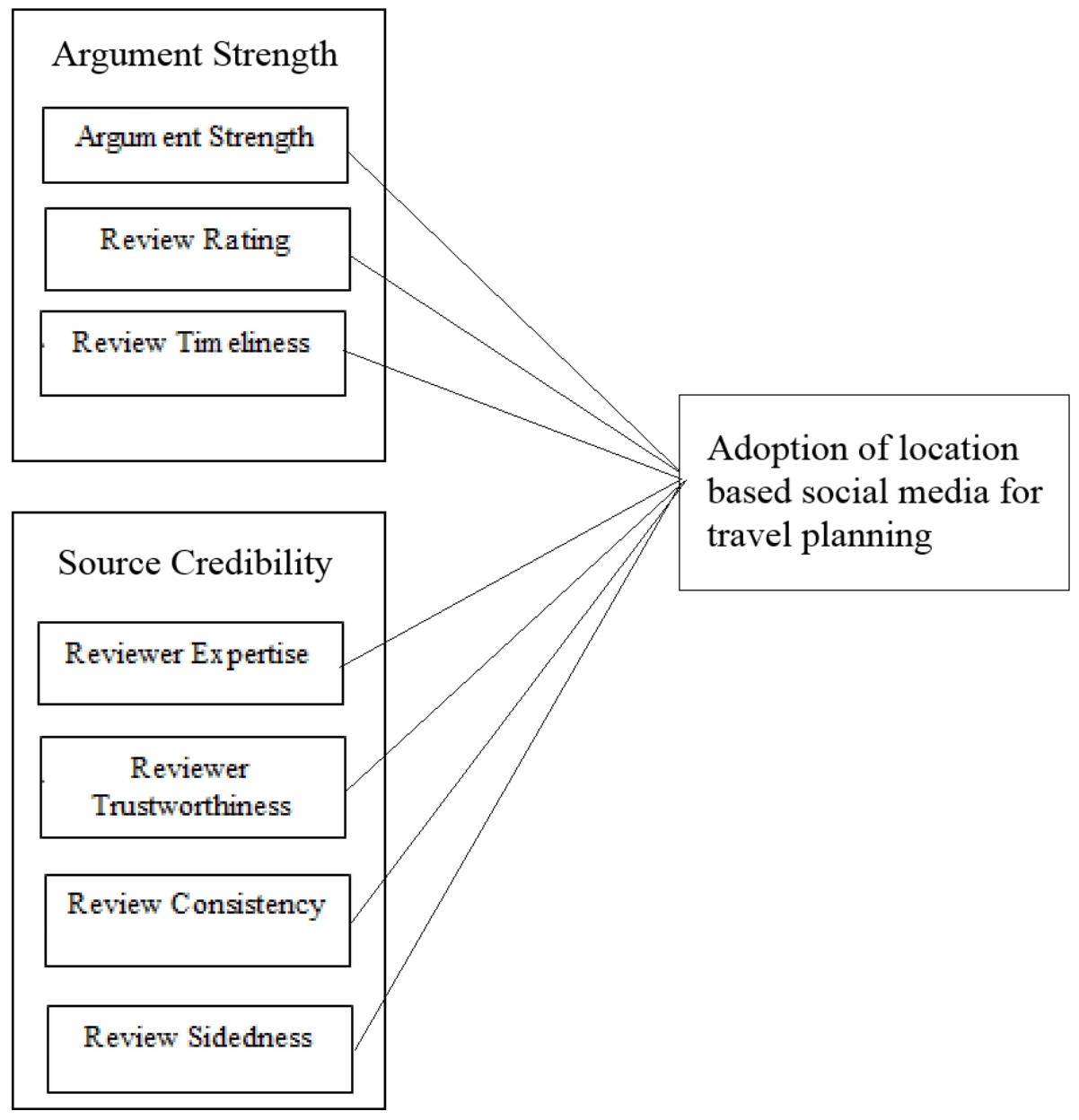

\section{METHODOLOGY}

\subsection{Data collection and sampling}

A survey questionnaire was developed to test our model. The survey was first translated into Chinese by a language instructor and later pre-tested by two university professors and a Phd student. Online surveys were collected from popular Chinese travel research Web sites, such as Qyer.com. Respondents were asked to familiarize themselves with the questionnaire content and to respond to the survey accordingly. 234 responses were collected for this study. The survey respondents included 123 males and 111 females, with an average age of 24 years. The respondents have also experienced using mobile Internet for the last 53 months.

\subsection{Measurement}

All variables were measured using a 7 point Likert scale (where 1 was "strongly disagree" and 7 was "strongly agree"). There are total of seven independent variables used in this study, and there are 22 items measuring the seven independent variables. Adoption of mobile location based social media for travel planning is measured using 3 items.

3.3. Validity and Reliability Analysis 
Convergent validity was examined based on the AVE values of the constructs. As show in Table 1, all AVE values are higher than the minimum requirement of 0.50 , thus demonstrating high levels of convergent validity.

Table 1 AVE and Composite Reliablity

\begin{tabular}{ccc} 
& AVE & $\begin{array}{c}\text { Composite } \\
\text { Reliability }\end{array}$ \\
\hline $\begin{array}{c}\text { Adoption of } \\
\text { LBSM for } \\
\text { Travel Planning } \\
\text { Argument }\end{array}$ & 0.777 & 0.913 \\
$\begin{array}{c}\text { Strength } \\
\text { Review }\end{array}$ & 0.803 & 0.942 \\
$\begin{array}{c}\text { Consistency } \\
\text { Review }\end{array}$ & 0.773 & 0.911 \\
$\begin{array}{c}\text { Rating } \\
\text { Review }\end{array}$ & 0.803 & 0.924 \\
$\begin{array}{c}\text { Sidedness } \\
\text { Review }\end{array}$ & 0.631 & 0.836 \\
$\begin{array}{c}\text { Timeliness } \\
\text { Reviewer }\end{array}$ & 0.829 & 0.936 \\
$\begin{array}{c}\text { Expertise } \\
\text { Reviewer }\end{array}$ & 0.752 & 0.901 \\
Trustworthiness & 0.827 & 0.935 \\
\hline
\end{tabular}

Fornell-Larcker criterion was used to check for discriminant validity. As shown in Table 2, the square root of the AVE of each construct (in bold) are higher than the constructs' diagonal and correlations between constructs in the table, thus providing support for the constructs' discriminant validity. The internal consistency reliability of the measurements is also confirmed by the composite reliability which all are greater than 0.70 .

Table 2 Cross loadings and Fornell-Larcker Criterion 


\begin{tabular}{|c|c|c|c|c|c|c|c|c|}
\hline & $\begin{array}{l}\text { Adoption } \\
\text { of LBSM } \\
\text { for } \\
\text { Travel } \\
\text { Planning }\end{array}$ & $\begin{array}{l}\text { Argument } \\
\text { Strength }\end{array}$ & $\begin{array}{c}\text { Review } \\
\text { Consistency }\end{array}$ & $\begin{array}{l}\text { Review } \\
\text { Rating }\end{array}$ & $\begin{array}{c}\text { Review } \\
\text { Sidedness }\end{array}$ & $\begin{array}{c}\text { Review } \\
\text { Timeliness }\end{array}$ & $\begin{array}{l}\text { Reviewer } \\
\text { Expertise }\end{array}$ & $\begin{array}{c}\text { Reviewer } \\
\text { Trustworthiness }\end{array}$ \\
\hline $\begin{array}{l}\text { Adoption of } \\
\text { LBSM for } \\
\text { Travel Planning }\end{array}$ & 0.882 & & & & & & & \\
\hline $\begin{array}{l}\text { Argument } \\
\text { Strength }\end{array}$ & 0.626 & 0.896 & & & & & & \\
\hline $\begin{array}{c}\text { Review } \\
\text { Consistency }\end{array}$ & 0.529 & 0.636 & 0.879 & & & & & \\
\hline $\begin{array}{l}\text { Review } \\
\text { Rating }\end{array}$ & 0.662 & 0.737 & 0.637 & 0.896 & & & & \\
\hline $\begin{array}{l}\text { Review } \\
\text { Sidedness }\end{array}$ & 0.660 & 0.614 & 0.685 & 0.589 & 0.794 & & & \\
\hline $\begin{array}{r}\text { Review } \\
\text { Timeliness }\end{array}$ & 0.604 & 0.619 & 0.693 & 0.629 & 0.656 & 0.910 & & \\
\hline $\begin{array}{l}\text { Reviewer } \\
\text { Expertise }\end{array}$ & 0.598 & 0.694 & 0.614 & 0.681 & 0.620 & 0.636 & 0.867 & \\
\hline $\begin{array}{c}\text { Reviewer } \\
\text { Trustworthiness }\end{array}$ & 0.616 & 0.722 & 0.719 & 0.717 & 0.601 & 0.669 & 0.735 & 0.909 \\
\hline
\end{tabular}

\section{RESULTS}

Table 3 Significance Testing Results of the Structural Model Path Coefficients

\begin{tabular}{ccccc}
\hline & $\begin{array}{c}\text { Path } \\
\text { Coefficients }\end{array}$ & $\begin{array}{c}\text { t- } \\
\text { values }\end{array}$ & $\begin{array}{c}\mathbf{p} \\
\text { values }\end{array}$ & $\begin{array}{c}\text { Significance } \\
\text { Levels }\end{array}$ \\
\hline Argument Strength -> Adoption & 0.106 & 1.115 & 0.214 & N.S. \\
Review Consistency -> Adoption & -0.171 & 2.052 & 0.049 & $* *$ \\
$\quad$ Review Rating -> Adoption & 0.277 & 3.279 & 0.002 & $* *$ \\
Review Sidedness -> Adoption & 0.358 & 4.542 & 0.000 & $* *$ \\
Review Timeliness -> Adoption & 0.137 & 1.462 & 0.137 & N.S. \\
Reviewer Expertise -> Adoption & 0.037 & 0.411 & 0.367 & N.S. \\
Reviewer Trustworthiness -> & & & & \\
$\quad$ Adoption & 0.130 & 1.375 & 0.155 & N.S. \\
\hline
\end{tabular}

Note: $\mathrm{NS}=$ not significant

$* * \mathrm{P}<0.05 * * * \mathrm{P}<0.001$

We performed our analysis using Smart PLS 2.0. Based on our result, Review Consistency, Review Rating and Review Sidedness have a significant relationship with users' adoption of location based social media for travel planning. Both review rating and review sidendess have positive relationships with adoption of location based social media for travel, while somewhat surprising, review consistency have a negative relationships with the adoption of location based social media for travel.

\section{DISCUSSION}


This research examined the factors that influence the adoption of location- based social media for travel planning with theoretical background on argument strength and source credibility. Location-based social media is currently a growing technology which has a great impact on the travel industry. When e-commerce first became widespread, the travel industry's (e.g. airline, hotels, travel agencies) competitive structure and business models were affected, requiring many companies to adapt to using the technology. Thus it is important for travel businesses to understand how the growing technology of location-based social media can influence their market and their competition, and a starting point is to understand what will influence consumers to adopt the technology.

Our findings also show that the review ratings, review sidedness, and review consistency can influence a user's decision to adopt location-based social media for travel planning. The roles of review sidedness has the strongest effect on users' intention to adoption location based social media, and this is different from findings from those such as Cheung et al. (2009) who find that review sidedness do not affect online credibility of electronic word of mouth. Nevertheless, the findings of review ratings and review consistency are similar to the findings from Cheung et al. (2009), Lu et al. (2013) and Chevalier and Mayzlin (2006). However, these studies have focused on the roles of review rating on product sales, and not the actual travel decisions after examining the review ratings and review consistency on location based social media. Interestingly, users who do not find reviews are consistent are more likely to adoption their travel planning based on the reviews. This shows that users perhaps place more trust on reviews which are not consistent and then form their own opinions from that, instead of wanting to look at reviews which offer similar and consistent opinions.

\section{IMPLICATIONS}

This study contributes to extant literature on location-based social media and technology adoption in several ways. Firstly, existing studies on online reviews emphasize the importance of argument quality and credibility in consumer acceptance of review information. However, very few studies show which aspects or what attributes of argument quality and credibility can influence the adoption of online reviews. This research examined the attributes of argument quality and credibility by examining argument strength, review rating, reviewer expertise, reviewer trustworthiness, review consistency, review sidedness, and review timeliness.

Secondly, mobile commerce and social media are currently in a crucial implementation stage in China (Chong et al. 2012). Although many firms, including the Chinese government, have invested a large amount of effort and finance in the mobile commerce market, development and implementation growth are still very slow. This research aims to provide a scientific, empirical study to understand the factors that will influence the location-based social media adoption decisions of consumers. Our findings can provide practitioners with guidelines and strategies that will ensure higher success rates in location-based social media implementation. Understanding why consumers adopt location-based social media in their travel planning is important for the survival and growth of location-based social media application developers while helping organizations improve their e-marketing strategies. Various new location-based social media applications are now being developed and introduced, and our study shows that review consistency (the lack of), sidedness and rating will enhance the adoption of locationbased social media and potentially attract repeat visits to location-based social media applications. Application developers should also ensure that the location-based social media is designed to provide useful travel information. Clearly, social influence plays a very important role in the adoption of location-based social media. Therefore, companies intending to use 
location-based social media as a marketing tool can provide incentives for users to share and promote the application. Having more users will not only influence the social circles of these users to adopt location-based social media, but will also enhance the value and usefulness of the application.

Thirdly, this study also has practical implications for travel companies. With location-based social media, travelers can rely less on travel companies when making travel decisions. Our study shows that travelers are likely to adopt and use location-based social media in their travel planning. Therefore, in addition to having e-commerce Web sites, as many travel companies now do, these companies should also develop location-based social media applications as another channel to interact with other travelers. 